Pak. j. sci. ind. res. Ser. A: phys. sci. 201154 (2) 98-102

\title{
Lead Concentration in Road Side Dust and Selected Vegetables of Lahore City, Pakistan
}

\author{
Naz Imtiaz ${ }^{a}$, Tahir Butt ${ }^{a *}$, Muhammad Irfan ${ }^{a}$, Tahira Shafiq ${ }^{a}$ and Arshad Chaudhry ${ }^{b}$ \\ ${ }^{\mathrm{a}}$ Centre for Environmental Protection Studies, PCSIR Laboratories Complex, Lahore-54600, Pakistan

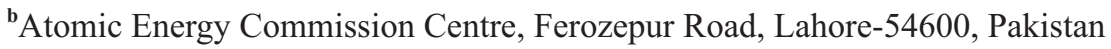

(received November 12, 2010; revised April 2, 2011; accepted April 14, 2011)

\begin{abstract}
The contents of lead as a pollutant in road side dust and vegetable samples of urban and rural areas of Lahore city, Pakistan, were monitored with the help of atomic absorption spectrophotometer. Average concentration of lead in dust samples collected from residential areas was 25 to $165 \mathrm{mg} / \mathrm{L}$, from rural areas 9.5 to $13.0 \mathrm{mg} / \mathrm{kg}$, from commercial areas 201 to $1685 \mathrm{mg} / \mathrm{kg}$, and from canal side 105 to $220 \mathrm{mg} / \mathrm{kg}$. In most of the vegetable samples, lead level was in the permissible range, whereas in some samples, the average lead concentration ranged from 0.13 to $5.0 \mathrm{mg} / \mathrm{L}$.
\end{abstract}

Keywords: lead, vegetables, soil

\section{Introduction}

Lead is distributed widely in nature in different forms because of its easy working qualities and permanence. It is used in batteries, cable sheaths, solder, radiation shielding etc. The widespread uses of lead in manufacturing of tetraethyl antiknock agents and paint pigments such as white lead, red lead and chrome yellow etc. led to environmental and health problems. It is difficult to know the natural lead level in the presence of human activities. In natural conditions lead is estimated to be $0.01 \mathrm{mg} / \mathrm{kg}$ in food, $0.0005 \mathrm{mg} / \mathrm{kg}$ in water,and $0.15 \mathrm{mg} / \mathrm{m}^{3}$ in air (Maharachpong et al., 2006; De, 1996). Lead levels in air vary with location and weather. In water, lead is derived from soil and rocks, fallout, dust and vehicular exhausts. Lead is widely distributed in food, with the widest variation in root and green vegetables. This variation reflects the contamination of soil by domestic and industrial fallout. Lead in vegetables and fruits cannot be removed by washing (Beg et al., 1987). In soil and dust, it is recognized as a public health problem and permissible lead levels in the soil have been proposed (RodriguezFlores and Rodriguez-Castellon, 1982). Lead is cumulative body poison (Wahlin et al., 2006). There are three means, by which lead enter our body system through air, water and food and produce toxic symptoms. The toxicity of lead has been studied extensively in recent years at trace and sub trace levels, by many countries on continuous basis to keep a check on their

*Author for correspondence; E-mail: pcsir322@gmail.com natural food supply before use (Wei and Yang, 2010). Mild level lead poisoning causes anemia, headache, fatigue and irritation. Acute lead poisoning in humans leads to severe damage of kidney, liver, brain, central nervous system, reproductive organs and sometimes to death. However, toxicity of lead compounds depends on their solubility in body fluids. The smaller is the particle size, the greater is its solubility and hence the toxicity. All these facts cause great concern for public health, demanding accurate determination of this metal ion at different sites, in different vegetables and items of human use so as to be able to avoid potential human health risk (Shi et al., 2011).

Techniques principally used for the determination of trace concentrations of lead are atomic absorption spectroscopy, colorimetry, polarography and emission spectroscopy and inductively coupled plasma. In this presentation lead is determined in roadside dust and vegetable samples by atomic absorption spectrophotometry as it is essentially a trace analysis technique and is one of the most powerful tools in chemical analysis, due to it rapidness, high sensitivity, specificity and being relatively free from interferences (Khairy et al., 2011).

\section{Materials and Methods}

Sampling. Forty samples of road side dust were collected along the intersection of major roads, residential, commercial and rural areas. Samples were also collected from pavements, side gutters and sidewalks, where traffic density was high or low. Twenty three samples 
of various vegetables were collected from different rural and urban areas of Lahore city including high ways, motor way and bund road (Brown, 1986).

Sample digestion. Soil/dust samples were collected and pulverized to pass through a 100 mesh sieve and dried at 105 to $110^{\circ} \mathrm{C}$ to constant weight. Sample (2-5 g) was mixed with $10 \mathrm{~mL}$ of concentrated nitric acid in a beaker then heated gently. Again $10 \mathrm{~mL}$ of concentrated nitric acid and $10 \mathrm{~mL}$ of $70 \%$ perchloric acid were added and the mixture was boiled until the solution became almost colourless. The mixture was heated to reduce the volume down to $2-3 \mathrm{~mL}$ then cooled. $10 \mathrm{~mL}$ of water was added and warmed to dissolve the salts. Samples were filtered, volume was made $100 \mathrm{~mL}$ using distilled water and the so prepared solution was used for analysis.

All vegetable samples were oven dried at $130-150^{\circ} \mathrm{C}$, grinded and $2 \mathrm{~g}$ of each sample in $250 \mathrm{~mL}$ beaker was treated with $5 \mathrm{~mL}$ of nitric acid. The beaker was covered with watch glass and heated on hot plate. After $1 \mathrm{~h}$, the contents of beaker were treated with further $5 \mathrm{~mL}$ of nitric acid and $1-2 \mathrm{~mL}$ of $35 \%$ hydrogen peroxide was added while swirling the contents. The heating was continued until the volume of the sample was reduced down to 2-3 mL. It was then cooled, filtered using Whatman filter paper \# 42 and volume was made $100 \mathrm{~mL}$ with double distilled water in a $100 \mathrm{~mL}$ volumetric flask. A blank was prepared using the same procedure (Brown, 1986). The samples were analyzed by atomic absorption spectra 40 Varian Australia (Lu et al., 2009). Calibration graph was prepared using stock solutions of lead.

\section{Results and Discussion}

The samples were analyzed using atomic absorption spectra and calibration graph was prepared using stock solution of lead which was linear passing through the origin (Fig. 1), in the range of 0.1 to $10 \mathrm{mg} / \mathrm{kg}$ of lead (Paoletti et al., 1991). WHO limit of lead in soil as a reference value is $13 \mathrm{mg} / \mathrm{kg}$ (Faiz et al., 2009). Comparison of various areas shows average concentration of lead to increase from $25 \pm 0.17$ to $165 \pm 0.20 \mathrm{mg} / \mathrm{kg}$ in the residential areas, far away from the freeways (Table 1). In the rural areas, lead was the lowest (Fig. 2) ranging from $9.5 \pm 0.20$ to $13 \pm 0.12 \mathrm{mg} / \mathrm{kg}$ within the WHO limits (Table 2); the reason is the low traffic density corresponding to the distance of the rural areas from the main city (Wahlin et al., 2006). Maximum concentration of lead was found in the commercial areas of Lahore ranging from $201 \pm 0.41$ to $1685 \pm 0.94$ $\mathrm{mg} / \mathrm{kg}$ (Table 3). Commercial areas of Lahore are mostly surrounded by multi-storey buildings which act as sink

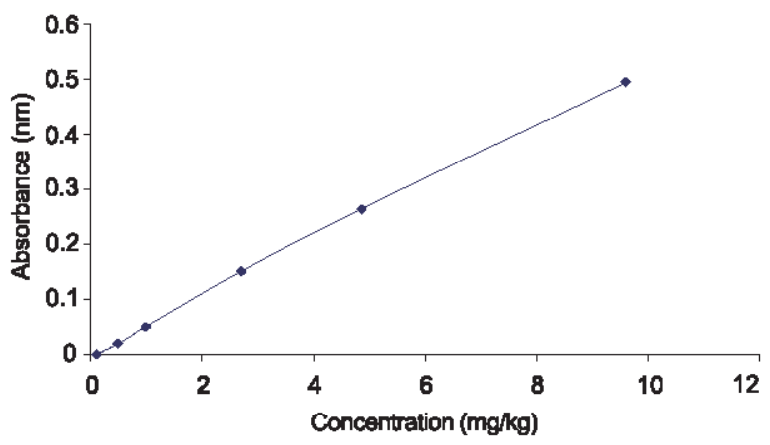

Fig. 1. $\mathrm{Pb}(\mathrm{II})$ calibration curve.

Table 1. Lead concentration in dust samples of residential areas of Lahore

\begin{tabular}{|c|c|c|}
\hline $\begin{array}{l}\text { Sample } \\
\text { no. }\end{array}$ & $\begin{array}{l}\mathrm{Pb} \text { concentration } \\
(\mathrm{mg} / \mathrm{kg})\end{array}$ & Sampling areas \\
\hline S-1 & $50.0 \pm 0.26$ & Muslim Town, Ferozepur Road \\
\hline S-2 & $129.0 \pm 0.24$ & Qaudri Cowk Township \\
\hline S-3 & $75.0 \pm 0.16$ & Johar Town \\
\hline S-4 & $25.0 \pm 0.17$ & College Road, Township \\
\hline S-5 & $156.0 \pm 0.21$ & Garden Town \\
\hline S-6 & $<1 \pm 0.02$ & Blank \\
\hline S-7 & $135.0 \pm 0.17$ & Model Town \\
\hline S-8 & $165.0 \pm 0.20$ & Johar Town, Main Road \\
\hline S-9 & $156.0 \pm 0.17$ & Misri Chowk \\
\hline S-10 & $115.0 \pm 0.17$ & Main Defence Road \\
\hline S-11 & $120.0 \pm 0.26$ & Defence Road Hospital \\
\hline S-12 & $130.0 \pm 0.26$ & Defence Road School \\
\hline
\end{tabular}

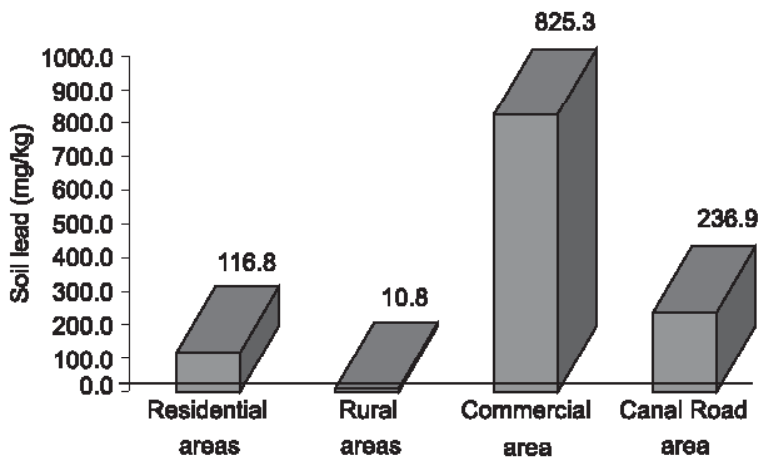

Fig. 2. Average $\mathrm{Pb}$ concentration in different areas of Lahore. 
Table 2. Lead concentration in dust samples of rural areas of Lahore

\begin{tabular}{|c|c|c|}
\hline S. no. & $\begin{array}{l}\mathrm{Pb} \text { concentration } \\
(\mathrm{mg} / \mathrm{kg})\end{array}$ & Sampling area \\
\hline S-1 & $10.0 \pm 0.20$ & Rice field, near Rohi Nallah \\
\hline S-2 & $13.0 \pm 0.25$ & $\begin{array}{l}\text { Wheat field, village } \\
\text { Kamahan }\end{array}$ \\
\hline S-3 & $\begin{array}{l}9.5 \pm 0.20 \\
\text { Harpalkey }\end{array}$ & Rice field, village \\
\hline S-4 & $11.0 \pm 0.26$ & Wheat field, village Leel \\
\hline S-5 & $<1 \pm 0.02$ & Blank \\
\hline S-6 & $13.0 \pm 0.12$ & Corn field, badian \\
\hline S-7 & $9.5 \pm 0.17$ & Defence Bhatta Chowk \\
\hline S-8 & $9.7 \pm 0.09$ & $\begin{array}{l}\text { Sugar cane from State Life } \\
\text { Agricultural land }\end{array}$ \\
\hline
\end{tabular}

Table 3. Lead concentration in dust samples of commercial area of Lahore

\begin{tabular}{lll}
\hline S. no. & $\begin{array}{l}\text { Pb concentration } \\
(\mathrm{mg} / \mathrm{kg})\end{array}$ & Sampling area \\
\hline S-1 & $850.0 \pm 1.24$ & Ichhra School Ferozepur Road \\
S-2 & $895.0 \pm 0.81$ & Ichhra Bus stop \\
S-3 & $870.0 \pm 0.81$ & Garden Town Bus stop \\
S-4 & $790.0 \pm 0.82$ & Model Town Bus stop \\
S-5 & $710.0 \pm 0.82$ & Ittifaq Hospital \\
S-6 & $201.0 \pm 0.41$ & PCSIR Bus stop \\
S-7 & $670.0 \pm 0.47$ & Waltan Road R.A Bazar \\
S-8 & $795.0 \pm 0.94$ & Sadar Road \\
S-9 & $<1 \pm 0.02$ & Blank \\
S-10 & $806.0 \pm 0.47$ & Dharampura Main Road \\
S-11 & $816.0 \pm 0.41$ & Railway Station \\
S-12 & $1685 . \pm 0.94$ & Ravi Road \\
\hline \hline
\end{tabular}

of pollutants. The increase in lead pollution may be due to the large traffic volume, emitting substantial quantity of lead along with smoke and other unwanted gases. It is concluded that soil along the roads having heavy traffic load contains more lead as compared to that of other areas.

The concentration of lead along the Lahore canal ranged from $105 \pm 0.82$ to $220 \pm 0.82 \mathrm{mg} / \mathrm{kg}$ (Table 4). This may be due to the location of the site, being relatively open with wide roads, covered on both the sides by large trees and vegetation. Although deposition of lead depends on traffic density, but it may be influenced by many factors such as wind velocity and direction, precipitation and humidity (Faiz et al., 1996). It was
Table 4. Lead concentration in dust samples of Canal Road area

\begin{tabular}{lll}
\hline S. no. & Pb concentration $(\mathrm{mg} / \mathrm{kg})$ & Sampling area \\
\hline S-1 & $210.0 \pm 0.82$ & Fatah Garh \\
S-2 & $220.0 \pm 0.82$ & Mughalpura \\
S-3 & $130.0 \pm 0.94$ & Dharampura \\
S-4 & $195.0 \pm 0.82$ & Herbanspura \\
S-5 & $114.0 \pm 0.94$ & Taj Pura \\
S-6 & $150.0 \pm 1.24$ & Lal Pul \\
S-7 & $200.0 \pm 0.82$ & Punjab University \\
S-8 & $143.0 \pm 0.82$ & Shah the Khoi \\
S-9 & $201.0 \pm 1.25$ & Jallo Road \\
S-10 & $<1 \pm 0.02$ & Blank sample \\
S-11 & $105.0 \pm 0.82$ & Jallo Park \\
S-12 & $142.0 \pm 0.82$ & Mall Road \\
\hline \hline
\end{tabular}

Table 5. Lead concentration in vegetable samples collected from rural and urban areas of Lahore

\begin{tabular}{lll}
\hline \hline S. no. & Vegetables & Pb concentration $(\mathrm{mg} / \mathrm{kg})$ \\
\hline 1. & Onion (U) & $0.32 \pm 0.02$ \\
2. & Spanich (U) & $4.2 \pm 0.12$ \\
3. & Mint (U) & $0.3 \pm 0.03$ \\
4. & Mustard (U) & $5.0 \pm 0.21$ \\
5. & Potato (U) & $0.56 \pm 0.12$ \\
6. & Radish (U) & $0.13 \pm 0.02$ \\
7. & Turnip (U) & $0.35 \pm 0.02$ \\
8. & Cauli flower (U) & $1.3 \pm 0.16$ \\
9. & Carrot (U) & $0.52 \pm 0.04$ \\
10. & Pea (U) & -- \\
11. & Lettuce (U) & -- \\
12. & Coriander (U) & $2.99 \pm 0.07$ \\
13. & Maize (U) & $0.20 \pm 0.03$ \\
14. & Wheat (R)* & $0.15 \pm 0.03$ \\
15. & Rice (R)* & $0.13 \pm 0.02$ \\
16. & Ginger (U) & $0.20 \pm 0.03$ \\
17. & Brinjal (U) & $0.50 \pm 0.04$ \\
18. & Cucumber (U) & $0.30 \pm 0.04$ \\
19. & Tomato (U) & $0.25 \pm 0.02$ \\
20. & Lady finger (U) & $0.20 \pm 0.03$ \\
21. & Cabbage (PU) & $0.15 \pm 0.02$ \\
\hline \hline
\end{tabular}

$\mathrm{U}=$ urban area; $\mathrm{R}=$ rural area; all samples were taken along the Lahore Motor Way to Kalashah Kaku and Defence rural area to Badian Road, High Way and Bund Road; * = wheat and rice samples were collected from the rural areas, whereas all the rest of vegetables, from the urban areas. 
observed that the average concentration of lead in vegetables ranged from $0.13 \pm 0.02$ to $5.0 \pm 0.21 \mathrm{mg} / \mathrm{kg}$ (Table 5) and in some vegetables, lead was below the detection limit. The accumulation of lead in green vegetables may be due to the use of polluted water for irrigation, use of lead arsenate as insecticide/fungicide or due to the fertilizer impurities or atmospheric pollution. However, lead concentration was higher in leafy vegetables as compared to the root tubers and vegetables (Duong and Lee, 2011; Farmer, 1993).

Faiz et al. (2009) conducted a study on road pollution with respect to heavy metals in Islamabad Pakistan, in which average lead concentration was shown as $29 \pm 104 \mathrm{mg} / \mathrm{kg}$ while in the present study, samples from the residential areas (Table 1) have lower concentration of lead (minimum $25 \pm 0.17$ to maximum $165 \pm 0.20 \mathrm{mg} / \mathrm{kg}$ ). The minimum and maximum lead concentrations in the rural areas (Table 2) were $9.5 \pm$ $0.20 \mathrm{mg} / \mathrm{kg}$ and $13 \pm 0.12 \mathrm{mg} / \mathrm{kg}$, respectively, while there were very high concentrations of lead in commercial areas of Lahore (Table 3 ) as compared to the residential and rural areas; these results are also much higher than the results of Faiz et al. (2009) reported in his study. The results of commercial areas in our study are much higher conforming to the reports of Faiz et al. (2009). The reason for higher concentration of lead in Lahore is the heavy transport load and dense population of the city (Faiz et al., 2009; Han et al., 2008).

\section{Conclusion}

It is concluded from the data presented here that high level of lead is present in the road side dust and leafy vegetables of Lahore. Lead is directly/indirectly entering and continuously polluting the environment. The hazards of lead pollution especially in growing children require particular attention, because children absorb and retain about $50 \%$ of the ingested lead as compared to $8 \%$ absorbed and retained by adults.

\section{References}

Beg, M.A.A., Yousufzai, A.H.K., Mahmood, S.N. 1987. Air pollution in Karachi, Part I. Survey of smoke. Pakistan Journal of Scientific and Industrial Research, 30: 60-70.

Brown, D.R. 1986. Lead analysis in urban dust on St. Thomas, U.S. Virgin Islands. Atmospheric
Environment, 20: 1305-1307.

De, A.K. 1996. Environmental Chemistry, 263 pp., $3^{\text {rd }}$ edition, New Age International (P) Limited, New Delhi, India.

Duong, T.T.T., Lee, B.K. 2011. Determining contamination level of heavy metals in road dust from busy traffic areas with different characteristics. Journal of Environmental Managements, 92: 554562.

Faiz, Y., Tufail, M., Javed, M.T., Chaudhry, M.M., Siddique, N. 2009. Road dust pollution of $\mathrm{Cd}, \mathrm{Cu}$, $\mathrm{Ni}, \mathrm{Pb}$ and $\mathrm{Zn}$ along Islamabad Expressway, Pakistan. Microchemical Journal, 92: 186-192.

Faiz, A., Weaver, C.S., Walsh, M.P. 1996. Air Pollution from Motor Vehicles: Standards and Technologies for Controlling Emissions, 246 pp., The World Bank, Washington DC., USA.

Farmer, A.M. 1993. The effects of dust on vegetation: a review. Environmental Pollution, 79: 63-75.

Han, Y., Cao, J., Posmentier, E.S., Fung, K., Tian, H., An, Z. 2008. Particulate-associated potentially harmful elements in urban road dusts in Xi'an, China. A. Applied Geochemistry, 23: 835-845.

Khairy, M.A., Barakat, A.O., Mostafa, A.R., Wade, T.L. 2011. Multielement determination by flame atomic absorption of road dust samples in Delta Region, Egypt. Microchemical Journal, 97: 234-242.

Lu, X., Wang, L., Lei, K., Huang, J., Zhai, Y. 2009. Contamination assessment of copper, lead, zinc, manganese and nickel in street dust of Baoji, NW China. Journal of Hazardous Materials, 161: 10581062.

Maharachpong, N., Geater, A., Chongsuvivatwong, V. 2006. Environmental and childhood lead contamination in the proximity of boat-repair yards in southern Thailand. I. Pattern and factors related to soil and household dust lead levels. Environmental Research, 101: 294-303.

Paoletti, L., Diociauti, M., Falchi, M., Pisant, D., Ziemacki, G. 1991. Quantitative analysis of airborne breathable particles. A comparison between different analytical techniques. Atmospheric Environment, 25B: 237-242.

Rodriguez-Flores, M., Rodriguez-Castellon, E. 1982. Lead and cadmium levels in soil and plants near highways and their correlation with traffic density. Environmental Pollution Series B, Chemical and Physical, 4: 281-290.

Shi, G., Chen, Z., Bi, C., Wang, L., Teng, J., Li, Y., Xu, S. 2011. A comparative study of health risk of 
potentially toxic metals in urban and suburban road dust in the most populated city of China. Atmospheric Environment, 45: 764-771.

Wahlin, P., Berkowicz, R, Palmgren, F. 2006. Characterization of traffic-generated particulate matter in
Copenhagen. Atmospheric Environment, 40: 2151-2159.

Wei, B., Yang, L. 2010. Review article. A review of heavy metal contaminations in urban soils, urban road dusts and agricultural soils from China. Microchemical Journal, 94: 99-107. 